\title{
Antonio Guízar y Valencia, obispo y arzobispo de Chihuahua, y su influencia en la formación de un laicado católico ajeno a la resistencia armada
}

\author{
Antonio Guízar y Valencia, bishop and \\ archbishop of Chihuahua, and his influence on \\ the formation of a Catholic laity alien to armed \\ resistance
}

Juan González Morfín*

* Licenciado en Letras clásicas por la UNAM, Doctor en Teología por la Pontificia Universidad de la Santa Cruz y convalidado como Doctor en Historia del Pensamiento (Universidad Panamericana 2016). Ha sido profesor de distintas escuelas de educación media y superior, y actualmente es investigador de la Universidad Panamericana y profesor de Historia de la Cultura, Filosofia social y Antropología. Sacerdote desde el 2004. Autor de varios libros y artículos sobre relaciones Estado - Iglesia católica, así como de algunas traducciones del latín al español. Miembro del Sistema Nacional de Investigadores a partir de enero del 2019. Correo electrónico: jgonzalem@up.edu.mx

https://orcid.org/0000-0002-7278-7872

Historial editorial

Recibido: 08-octubre-2019

Aceptado: 14-enero-2020

Publicado: 31-enero-2020

ISSN-e: 2594-2956 
Antonio Guízar y Valencia, obispo y arzobispo de Chihuahua, y su influencia en la formación de un laicado católico ajeno a la resistencia armada

\section{Resumen}

Este trabajo analiza la influencia que tuvo el arzobispo Antonio Guízar y Valencia en el laicado católico de Chihuahua, especialmente en la época en que otros católicos del país optaron por resistir, a través de las armas, ciertas medidas del gobierno. El arzobispo Guízar gobernó la diócesis de Chihuahua durante 48 años. Durante su gobierno prohibió terminantemente el recurso a las armas para obtener cualquier tipo de reivindicación. Se mencionan algunos de sus escritos que permiten apreciar una firme convicción de que la opción armada era inmoral porque no haría sino aumentar la polarización de las facciones. Su opción por las vías legales y pacíficas conformó un laicado católico combativo pero ajeno a la resistencia armada.

Palabras clave: conflicto religioso, resistencia, ley, laicado. 
Antonio Guízar y Valencia, bishop and archbishop of Chihuahua, and his influence on the formation of a Catholic laity alien to armed resistance

\section{Abstract}

This work analyzes the influence that Archbishop Antonio Guízar y Valencia had on the Catholic laity of Chihuahua, especially at the time when other Catholics in the country chose to resist some government measures through an armed conflict. Archbishop Guízar was the head of the diocese of Chihuahua for 48 years. During his government, he strictly prohibited the use of weapons to win over any type of claim. Some of his writings allow us to appreciate his firm conviction that the armed option was immoral because it would only increase the polarization of the factions involved. His choice of legal and peaceful means formed a combative Catholic laity however alien to armed resistance.

Keywords: religious conflict, resistance, law, laity. 
Antonio Guízar y Valencia, évêque et archevêque de Chihuahua, et son influence sur la formation d'un laïcat catholique en dehors de la résistance armée

\section{Résumé}

Ce travail analyse l'influence que l'archevêque Antonio Guízar et Valence a eu sur les laïcs catholiques de Chihuahua, en particulier au moment où d'autres catholiques du pays ont choisi de résister à certaines mesures gouvernementales par les armes. L'archevêque Guízar a dirigé le diocèse de Chihuahua pendant 48 ans. Pendant son gouvernement, il a strictement interdit l'utilisation d'armes pour obtenir tout type de réclamation. Certains de ses écrits sont mentionnés, ce qui nous permet d'apprécier la ferme conviction que l'option armée est immorale car elle ne ferait qu'augmenter la polarisation des factions. Son option pour des moyens légaux et pacifiques a formé un laïcat catholique combatif mais inconscient de la résistance armée.

Mots-clés: Conflit religieux, Droit, Laics, Résistance 
Antonio Guízar i Walencja, biskup i arcybiskup Chihuahua oraz jego wpływ na tworzenie świeckiego oporu katolickiego

\section{Streszczenie}

Praca analizuje wpływ arcybiskupa Antonio Guízara i Walencji na katolickia komunidad Chihuahuy w czasie, gdy inni katolicy w kraju zdecydowali się oprzeć zbrojnie rzadowi federalnemu.. Arcybiskup Guízar rządził diecezją Chihuahua przez 48 lat. Podczas swojej kadencji surowo zakazał używania broni przeciwko rzadowi. W dokumentach przez siebie podpisanych wyraza przekonanie, że zbrojna opcja jest niemoralna, ponieważ moze zwiększyc polaryzacji spoleczenstwa. Wybral walke za pomocą legalnych i pokojowych środków ktorej rezultatem bylo wzmocnienie katolickiej wspólnoty.

Slowa kluczowe: Konflikt religijny, opór, prawo, sekularyzacja 


\section{Introducción}

En I92I, Chihuahua tenía 40I,522 habitantes y, a pesar de que la violencia revolucionaria había diezmado la población en muchos estados, en la entidad más grande del país apenas sí había variado respecto del censo de I9IO en que contaba con 405,707 (INEGI, I996). En estados como Guanajuato o Morelos, la población había descendido dramáticamente a causa del torbellino revolucionario y la llamada de las epidemias que diezmaban la población. ${ }^{\text {I }}$ Nos sirve conocer que en esos once años la población de nuestro estado permaneció sustancialmente idéntica, pues mientras que en I92I el censo no preguntó la religión a que pertenecían, en el de i9io se asentaba que 384,993 habitantes eran católicos; 4,592, evangélicos; I,059 de alguna otra religión y 5,769 decían no tener religión alguna. A esa diócesis llegó como obispo un sacerdote michoacano, oriundo de la pequeña ciudad de Cotija de la Paz, ${ }^{2}$ el 4 de febrero de I92I: don Antonio Guízar y Valencia, quien habría de permanecer a cargo de la diócesis hasta el 24 de agosto de $1969,{ }^{3}$ desarrollando uno de los pontificados más largos de la historia reciente en nuestro país. Sobra decir que durante los 48 años de su gestión necesariamente dejó una impronta memorable en su diócesis, que a partir de 1958 sería arquidiócesis y que más tarde comenzaría a dividirse, dando lugar a las diócesis de Ciudad Juárez y al vicariato apostólico de la Tarahumara.

Durante su largo periodo de gobierno, Antonio Guízar tuvo que sortear el largo conflicto entre la Iglesia católica y el Estado mexicano que alcanzó su clímax en la llamada Guerra Cristera, entre 1926 y I929, y que se prolongó a través de leyes restrictivas durante los años siguientes; prácticamente hasta mediados de 1937. En este diferendo, don Antonio

184 tomó decididamente cartas en el asunto para evitar que muchos católicos chihuahuenses, deseosos de recuperar la libertad que en materia religiosa se les estaba regateando, optaran por el camino de las armas como una ultima ratio para recuperar los derechos que se les estaban negando y que les parecían imposibles de abandonar. De entre los obispos partidarios de llegar a un acuerdo que permitiera la 
reanudación del culto, fue uno de los más combativos y, en la práctica, su predicación y su ejemplo consiguieron que sus feligreses no se inmiscuyeran en la defensa armada.

De manera tangencial, Meyer (1973) menciona la actitud enérgica del obispo Guízar para frenar el levantamiento programado por la Liga Nacional Defensora de la Libertad Religiosa ${ }^{4}$ a comienzos de 1927. El autor señala cuán propicio hubiera sido, al menos por la condiciones externas, un levantamiento en un estado con una orografía tan complicada para perseguir grupos rebeldes, con villistas dispuestos a tomar las armas, con una magnífica organización por parte de la Liga para extender o sostener el movimiento y, sin embargo, el alzamiento no se dio por la firmeza del obispo. No obstante, Meyer no profundiza en las razones que motivaron al prelado. Tampoco se adentra mayormente en el papel que desarrolló para que se dieran los arreglos que permitieron destrabar el conflicto (Meyer, 2013). En este punto, es relevante el trabajo de Alcalá (20II), pues acude a los archivos vaticanos para mostrarnos hasta dónde fueron importantes las acciones de Guízar.

En este breve trabajo se buscará, por un lado, conocer mejor las motivaciones que condujeron al prelado de Chihuahua a mantener esa opción por apartar a los laicos del recurso de las armas como un medio para conseguir reivindicaciones y, por otro, esbozar el perfil cívico del católico, que resultó de la actuación del obispo Guízar y Valencia. Aunque el pontificado de nuestro personaje se extiende hasta fines de los años sesenta, nuestro estudio se desarrollará sobre todo en los primeros quince años de gobierno de Guízar, pues fue precisamente en ellos en los que con mayor frecuencia no pocos católicos consideraron la opción de levantarse en armas contra el gobierno establecido, como un modo de salvaguardar ciertos derechos religiosos que, a su juicio, se les estaban negando.

\section{Antecedentes del conflicto religioso en Chihuahua}


En I893 fue creada la diócesis de Chihuahua y se nombró como primer obispo a José de Jesús Ortiz López, quien después de ocho años de pontificado habría de ser trasladado como obispo de Guadalajara. Este prelado se significó, tanto en Chihuahua como en Guadalajara, por su promoción de la prensa católica y preocupación por que la naciente doctrina social de la Iglesia, en relación con los obreros, se viera hecha realidad lo más pronto posible, ${ }^{5}$ siempre en colaboración con las autoridades constituidas, según se desprende de la carta que dirigió a sus nuevos feligreses de Guadalajara. En ella elogia la situación de armonía entre el régimen porfirista y la Iglesia católica e invita a secundar la obra del gobierno:

Vivimos seguros de que, buscando de preferencia el reino de Dios y su justicia, sin necesidad de inconsideradas extralimitaciones, prestaremos el más eficaz apoyo a la obra de regeneración con tanto acierto iniciada por los hombres de Estado que hoy tienen en su mano las riendas del Gobierno, y a cuyas altas dotes de inteligencia y energía, de patriotismo y justificación, débese en gran parte la situación bonancible de la cosa pública (Ortiz, I90I, p. I68).

Así, durante su breve pontificado en Chihuahua, José de Jesús Ortiz López dejó sentada una estrategia de extender la doctrina social sin confrontaciones con el poder público, situación que prevalecía cuando asumió la diócesis el obispo Guízar y Valencia. ${ }^{6}$ Su llegada a la diócesis daba fin a un periodo de casi cinco años de ausencia virtual del prelado ordinario y un año de sede vacante. En efecto, su antecesor, Nicolás Pérez Gavilán, había tenido que refugiarse en la Ciudad de México durante los años de la revolución constitucionalista y, a su regreso a 186 Chihuahua, había permanecido encerrado en su casa a consecuencia de una parálisis y otras afecciones de salud.

La primera ocupación de Guízar, una vez que hubo tomado posesión, fue la de rehabilitar el seminario, siguiendo el consejo que le había dado su hermano Rafael, obispo de Veracruz: "A un obispo le puede faltar 
catedral, le puede faltar mitra, le puede faltar báculo, pero nunca le puede faltar seminario" (Belgodere y Havers, 1993, p. 257). Junto con esto, se dio a la tarea de reorganizar a los laicos. En 1925, se puso en contacto con el obispo auxiliar de Morelia para que, a través de Adalberto Abascal (AHAM, 1925), se iniciara en Chihuahua la Asociación del Espíritu Santo, mejor conocida como "la U", una organización secreta que se proponía como fines la defensa de la Iglesia y de los católicos así como la implantación del orden social cristiano en todo el país (Solis, 2008). Al mismo tiempo, la recientemente creada Liga Nacional Defensora de la Libertad Religiosa comenzó a extenderse con una rapidez inusitada en el estado de Chihuahua, de forma que, para junio de 1925, cuando a nivel nacional la Liga apenas contaba con cerca de 36,000 miembros, "4,000 eran de Chihuahua y, en 1926, contaba en ese estado con 35 centros y 72 secciones" (Meyer, 20I3, p. 339). Para darse una idea, habría que decir que ni siquiera en el Distrito Federal había tantos centros y que el total de miembros en la capital de la República era 3,500 (Meyer, I973).

A diferencia de otros lugares en que la Liga se había nutrido en buena parte de ex integrantes del extinto Partido Católico Nacional, en Chihuahua no ocurría eso, pues apenas sí había tenido presencia en el estado dicho organismo (O’Dogherty, 200I). Esto significa, entre otras cosas, que los recién reclutados militantes, ya fueran de la U o de la Liga, no necesariamente tenían antecedentes políticos y su disposición a plegarse a las instrucciones del prelado sería necesariamente mayor que la de aquellos que perseguían, junto con mayores libertades para la Iglesia, sobre todo un ideal político. ${ }^{7}$

En 1926, el gobierno del general Plutarco Elías Calles comenzó a exigir que se cumplieran preceptos constitucionales que Carranza, De la Huerta y Obregón habían preferido no aplicar. Así, entre febrero y marzo de ese año, se cerraron decenas de colegios católicos, se expulsaron casi doscientos sacerdotes extranjeros, se confiscaron propiedades a la Iglesia, se consignó, aunque sin éxito, al arzobispo de México por un supuesto delito de sedición y, sobre todo, se presionó a las legislaturas estatales para que, de acuerdo a la fracción VII del 
artículo 130 constitucional, se determinara un número máximo de ministros de culto en cada entidad federativa, por lo que las leyes que restringían el número de sacerdotes que podían ejercer su ministerio se multiplicaron en pocos meses. Además, los sacerdotes tenían que registrarse ante las autoridades civiles para recibir de ellas el permiso de ejercer su ministerio (González, 2017a). Por otro lado, el presidente Calles, que en enero de 1926 había recibido facultades especiales del Congreso para reformar el Código penal, presentó su proyecto el i4 de junio y lo publicó en el diario oficial el 2 de julio siguiente. Su reforma al código consistía sustancialmente en castigar penalmente, con multas, cárcel o ambas, a quienes infringieran las leyes establecidas en materia de culto, como las que reducían el número de sacerdotes y exigían su registro para que pudieran ejercer su ministerio.

Aunado al intento fallido de 1925 de crear una iglesia cismática, este hecho fue visto como una estrategia gubernamental para someter a la Iglesia y ponerla a su servicio, por lo que algunos obispos promovieron la suspensión del culto público en todo el país antes que obedecer una ley que supuestamente les iba a quitar la libertad mínima que necesitaban. Aunque no todos los obispos apoyaban esta postura (Valvo, 20I6), fue la que prevaleció en ese momento y, a partir del último día de julio de 1926, en todas las iglesias del país se suspendió el culto, incluidas las de Chihuahua, a pesar de que el obispo Guízar no había estado de acuerdo con la decisión tomada. Partidario, como era, de evitar una probable escalada hacia la violencia, presagiaba que nada bueno podía conllevar una medida tan radical.

\section{La acción de Antonio Guízar y Valencia para prevenir un conflicto armado}

Una vez cerrados los templos, la presión que ya se había venido dando de parte de los católicos para exigir la derogación de la llamada "Ley Calles" se incrementó al máximo. En diversos puntos del país hubo motines y zafarranchos, incluso muertos (Meyer, 1973). La tensión se incrementó cuando el gobierno de Calles comenzó a perseguir, sin que 
mediara ley alguna que lo prohibiera, el culto privado, esto es, a los sacerdotes que celebraban algún sacramento no en los templos, sino en casas particulares. Hubo arrestos y deportaciones a Islas Marías, colonia penal conocida por la precariedad de sus condiciones. En esta situación, no pocos pensaron en la oportunidad de un levantamiento armado que pusiera fin a ese estado de cosas. El obispo, al enterarse, escribió inmediatamente al Comité episcopal para expresar cuál era su opinión:

He juzgado y juzgo firme y sinceramente que URGE que ese V. Comité repruebe pública y francamente, por escrito, la rebelión contra las Autoridades constituidas en el orden civil, como medio para conseguir la solución de las dificultades religiosas en nuestra patria (AHAM, 1926, caja I47, expediente 5).

Guízar, a una semana de haberse iniciado la suspensión del culto, entreveía que los grupos radicales se aprovecharían del descontento para promover levantamientos armados contra el régimen de Calles y solicitaba del Comité episcopal que se atajara a tiempo esta posibilidad; sin embargo, el presidente del Comité, el arzobispo Mora y del Río, más bien se mostraba partidario de que la situación se polarizara al máximo para que el pueblo católico consiguiera la derogación de las leyes que afectaban a la Iglesia, si no es que incluso la caída del gobierno de Calles. ${ }^{8}$

El prelado de Chihuahua, no obstante que conocía el modo de pensar del arzobispo Mora, exponía claramente las razones por las que solicitaba esa intervención con carácter de urgente para desanimar a los católicos que planteaban el uso de las armas:

La rebelión por motivos religiosos traería las más funestas consecuencias para la religión y la patria, y esa revuelta sería sólo el primer eslabón de una cadena de guerras religiosas. Por esto creo que es nuestro deber y deber urgente, manifestar clara y sinceramente a los católicos mexicanos que guarden la paz y 
sigan sujetos a las autoridades civiles, como es su deber (AHAM, I926, caja I47, expediente 5).

A diferencia de muchos católicos -seglares y clérigos- que veían en el levantamiento armado no solo la última opción para rescatar las libertades perdidas, sino un camino accesible para instaurar un nuevo orden social, Guízar veía con toda clarividencia que una revuelta de carácter religioso enconaría más las posturas y sería el principio de una cadena de enfrentamientos que no llevarían a ningún lado. También era consciente de que la doctrina de la Iglesia católica siempre había recomendado a sus fieles obediencia y colaboración con las autoridades constituidas y resistencia pacífica a cualquier ley que considerasen injusta (González, 2009).

Por otro lado, veía también claramente que se podían buscar otros medios para conseguir la deseada derogación de las leyes:

Es evidente que tenemos medios rectos para conseguir las libertades en el orden religioso y de enseñanza: la oración, la penitencia y la vida cristiana en lo sobrenatural; las peticiones y los medios legales en lo humano, siempre dentro del respeto y sumisión debidos a las legítimas autoridades, usando los derechos que les da la ley civil a los ciudadanos (AHAM, I926, caja I47, expediente 5).

También estaba seguro de que, solamente a través de esos medios legales y pacíficos era que se podía llegar a una situación de concordia y unidad duraderas: "Por estos medios, más tarde o más temprano, lograremos las libertades que anhelamos y se verificará una labor de 190 armonía y de resultados sólidos y duraderos" (AHAM, I926, caja I47, expediente 5). Por la tanto, la única vía adecuada tenía que ser la de alentar la participación ciudadana a través de los cauces pacíficos previstos por el marco legal, aunque la solución tardara en llegar. 
En la carta también explicaba que él, en su diócesis, ya habría tomado esas medidas, pero que prefería no ir en discordancia con el resto de los obispos y, como creía que todos serían de su parecer, mejor permanecía en espera de que el mismo Comité episcopal lo hiciera para todo el país:

Yo, Ilmo. Sr., lo hubiera hecho ya en esta diócesis, pero dado que ese H. Comité tiene la dirección de estos asuntos, me ha parecido que debo esperar sus decisiones y por esto me limito a proponer a ese V. Comité lo que me parece debido y urgente (AHAM, I926, caja I47, expediente 5).

Si bien es verdad que pecaba de optimista, sin embargo, el hecho de que fijara su postura con esa contundencia permitió que otros obispos de su parecer se avivaran y comenzaran también a buscar una solución negociada con el gobierno, lo que originó la entrevista de dos prelados con el presidente Calles en el castillo de Chapultepec, el 2I de agosto de I926, y que no tuvo éxito (González, 20I6).

Tampoco tendría éxito el memorial presentado por los católicos mexicanos ante la Cámara de Diputados, solicitando la derogación de las leyes, lo que condujo a que amplios sectores del laicado pensaran que no había otra salida que el recurso a las armas. ${ }^{9}$

Las organizaciones de seglares católicos, bajo el liderazgo de la Liga, ${ }^{\text {Io }}$ comenzaron así los preparativos para un levantamiento a gran escala. Uno de los estados que preveían como bastión de la insurrección, era precisamente el de Chihuahua, debido tanto a la buena organización que le Liga había conseguido, como a que en dichas tierras habitaban muchos ex villistas y ex delahuertistas resentidos que podrían fácilmente sumarse al movimiento. Sin embargo, las expectativas de sumar Chihuahua al movimiento resultaron fallidas, pues don Antonio Guízar lo prohibió tajantemente, como había pedido que lo hiciera todo el episcopado, pues estaba convencido que cualquier sublevación únicamente atraería mayores males para México y para la Iglesia. 


\section{Cabildeo continuo de Guízar para conseguir un arreglo}

Durante los casi tres años que duró la llamada Guerra Cristera, ${ }^{\text {II }}$ el obispo Guízar no cejó en sus esfuerzos por conseguir la unidad de los prelados favorables a encontrar con el gobierno un acuerdo mínimo de garantías para la práctica religiosa, que les permitiera ordenar la reanudación del culto. Así se desprende de una carta del obispo Pascual Díaz, entonces secretario del Comité episcopal, al prelado de Chihuahua:

No me es desconocido el pavoroso problema que se está desarrollando con la suspensión indefinida de los cultos...; pero ¿qué puede hacerse si cuando apenas se habla de una posibilidad de arreglo surge un conjunto de voces airadas que clama y vuelve a clamar "itodo o nada!" que es el lema de un grupo de católicos, que pretenden ser la opinión del pueblo católico de México? ¿Qué puede hacer la Santa Sede, si los mismos interesados en el conflicto le dicen: "no queremos arreglos, queremos exclusivamente la reforma de las leyes previamente", y el gobierno se opone a hacer esa reforma previa? (AHAM, I926, caja I4, expediente I6).

Efectivamente, la situación se había tornado de lo más compleja. Los grupos más radicales, partidarios del "todo o nada", no aceptaban algún tipo de entendimiento que no fuera la derogación de las leyes que limitaban la acción de la Iglesia y estaban, no solamente dispuestos a proseguir la guerra, sino deseosos de continuar por ese camino. Por otro lado, los prelados como Díaz y Guízar observaban las severas consecuencias que la suspensión del culto estaba acarreando en la

192 feligresía y pugnaban por un acuerdo, el que fuera, que permitiera destrabar las cosas.

Así, desde San Antonio, Texas, en donde estaba desterrado, Guízar escribía buscando desarticular los argumentos de los partidarios del todo o nada. En primer lugar, quienes en diferentes ocasiones lograron 
boicotear los esfuerzos para llegar a un arreglo, sostenían que intentarlo, sin que se hubieran derogado las leyes antirreligiosas supondría, ipso facto, una complicidad de parte de los obispos, lo que causaría un grave escándalo en la comunidad de los creyentes. Ante esa objeción, Guízar argumentaba que:

[...] ningún obispo mexicano ha tenido la menor vacilación ni, con el favor de Dios, es de temerse que alguno aprobara o aceptara las leyes antirreligiosas. [Y en relación con] lo segundo, la mala interpretación del pueblo no es verosímil; porque consta que al haberse anunciado, hace unos dos meses, la vuelta de los prelados a la patria, el pueblo católico, sobre todo en la capital, se llenó de alegría y entusiasmo, sin juzgar mal en esto de los obispos (AHAM, I927, caja 47, expediente 28).

Guízar estaba convencido de que no pocos católicos, quizá permeados por los todavía recientes acontecimiento revolucionarios, no dejaban de ver en la opción armada un camino entre tantos para solucionar los problemas que se presentaran, cuando de acuerdo a la doctrina católica no era así, de hecho ya lo había manifestado abiertamente al arzobispo de México: "Tengo una convicción profunda de que una revuelta en nuestro caso no es un medio recto que usarán los católicos y es por esto necesario manifestarles que reprobamos tal medio" (AHAM, 1926, caja I47, expediente 5). Sus enseñanzas y su ejemplo se encaminaron, pues, en ese sentido y fueron especialmente importantes para formar el criterio de los católicos chihuahuenses en los años más álgidos del conflicto. A la postre, se mostrarían acertadas en sus premisas de que un levantamiento armado no haría sino enconar las posturas y causar graves daños al país.

Apenas iniciado el año I929, se multiplicaron sus esfuerzos para alcanzar las condiciones que permitieran un acuerdo entre las partes. El gobierno entrante de Portes Gil había exigido que los sacerdotes católicos y sus prelados se registraran y dieran sus domicilios. Esta medida, que había sido ya repudiada como una forma de control en épocas de paz, ahora, en tiempo de guerra y persecución, parecía una 
exigencia no solamente desproporcionada e injusta, sino incluso peligrosa. Sin embargo, don Antonio Guízar y Valencia se dio prisa en secundar la medida e hizo público que había cumplido con la exigencia gubernamental. ${ }^{\mathrm{I} 2}$ Comenzaba, así, a tender puentes para lograr un acercamiento.

\section{Los meses anteriores a los arreglos}

En febrero de 1929, después de veinte meses de destierro, Guízar regresa a su diócesis, aunque sin aparecer en público. El día io hubo un atentado dinamitero contra el tren en el que viajaba el presidente Portes Gil, cerca de la estación Comonfort, en el estado de Guanajuato. Aunque hubo algunos muertos y la máquina y dos carros quedaron destrozados, sin embargo, el presidente y sus acompañantes resultaron ilesos. Este acontecimiento le dio ocasión al obispo de Chihuahua para hacer unas declaraciones al diario El Universal en las que reprobaba la violencia como un medio de obtener cualquier tipo de reivindicaciones. Es interesante que tanto estas declaraciones, como el hecho de acudir a dar su domicilio ante las exigencias del gobierno, fueron dados a conocer por el diario vaticano de un modo sereno e, incluso, mostrando su simpatía por lo que estaba haciendo:

[...] el primero en notificar su domicilio fue el obispo de Chihuahua, Guízar y Valencia, de quien El Universal publicó una carta dirigida al presidente Portes Gil, en la que condena el atentado dinamitero en contra del presidente y le expresa sus congratulaciones por haber escapado del atentado (L'Osservatore Romano, I5 de marzo, I929, p. 2).

194 Alfonso Alcalá, quien ha estudiado meticulosamente este breve periodo que precedió a los arreglos, asegura que "tales declaraciones cayeron bien al presidente Portes Gil, el cual, movido además por algunas personas influyentes, invitó al obispo de Chihuahua a pasar a la capital para ver el modo de arreglar las disidencias con la Iglesia" (Alcalá, 20II, p. 2I8). 
El prelado tuvo, de esa forma, algunas entrevistas con el presidente, así como con el licenciado Ezequiel Padilla, secretario de educación, y algún otro político. Poco después, viajó a Washington y después a Roma, siempre con la idea de facilitar un entendimiento entre el gobierno y la jerarquía. Por más que sus gestiones sin duda coadyuvaron a que la Santa Sede tuviera un panorama más completo y actualizado de la situación en México, sin embargo, no tuvieron el éxito que Guízar esperaba (Valvo, 2016).

En cualquier caso, la prensa norteamericana estuvo pendiente de la actuación del obispo:

[...] se ha anunciado que el obispo Antonio Guízar Valencia, de la diócesis de Chihuahua, ha llegado a Roma a conferenciar con el Vaticano respecto a un arreglo. El obispo estaba en Washington al tiempo en el que el arzobispo Ruiz y Flores anunció la disposición de parte de las autoridades eclesiástica a cooperar con el presidente en los asuntos relativos al bienestar de los mexicanos (La Prensa, 1929, p. 2).

Como es sabido, el 2I de junio de 1929 culminaron las negociaciones con el gobierno, conducidas en su etapa final por los obispos Leopoldo Ruiz y Pascual Díaz, y se llegó a un modus vivendi conocido como "Los arreglos” (González, 20I5). Ese mismo día el obispo Guízar daba estas declaraciones para la prensa: “

Yo soy muy franco y me gusta decir las cosas claramente; por eso les suplico que pongan esta frase textual mía, interpretando mi sentir de católico y de mexicano para el actual presidente de la República: El señor licenciado Portes Gil, al responder a un anhelo de la Nación entera, ha conquistado la inmortalidad ( $E l$ Universal, 22 de junio, 1929, p. 2). 
Los años que siguieron a los arreglos y la reducción legal de sacerdotes en Chihuahua

Después de los arreglos vinieron algunos meses en que la vida religiosa se normalizó en Chihuahua. Los grupos más afines a la resistencia armada, como la ACJM, fueron orillados a afiliarse a la naciente Acción Católica, quedando por completo bajo las directrices pacifistas del obispo (Savarino, 20I7). En el resto del país, también se vivieron momentos de distensión en las relaciones entre el Estado y la Iglesia católico, con excepción de Veracruz y Tabasco. En Chihuahua, por su parte, aunque se sucedieron diversos gobernadores de tinte anticlerical, incluido Luis L. León, amigo personal de Calles, no se aplicaban las leyes restrictivas que habían sido aprobadas por el Congreso en junio de 1926.

En octubre de 1932 inició su mandato como gobernador el general Rodrigo M. Quevedo, personaje cercano a Plutarco Elías Calles, quien durante su periodo como gobernador avivó nuevamente el conflicto religioso con medidas radicales que restringían el culto religioso (INEHRM, 20I4).

Así, en marzo de I934 se promulgó una ley que permitía solo un ministro de culto por cada IOo,ooo habitantes, en total, cinco para todo el estado. En julio del mismo año, el Congreso expidió una segunda ley que reservaba al Ejecutivo estatal la facultad de autorizar a cualquier ministro de culto. En abril de 1936, la ley no permitía más que un sacerdote para todo el estado (Navarrete, 1957). En la práctica, no había culto sino únicamente en la clandestinidad.

196 Desde el destierro en el que se encontraba nuevamente, el obispo Guízar y Valencia prosiguió desalentando cualquier movimiento que implicara la violencia $y$, al mismo tiempo, aunque con pocas esperanzas, alentó a los laicos y a sus sacerdotes a seguir acudiendo a todas las instancias legales. Así, en 1937, la Segunda Sala de la Suprema Corte de Justicia de la Nación amparó a tres sacerdotes del estado de 
Chihuahua contra la ley publicada el 25 de abril de I936, que fijaba como máximo un sacerdote de cada credo en todo el estado. En la sentencia se explicaba un punto interesante:

Concedió el amparo por estimar que las autoridades responsables no justificaron sus actos, y porque la fijación en solo uno, del número de ministros de cada culto religioso que pueden oficiar en el Estado de Chihuahua, era contraria al espíritu del artículo I30 de la Constitución Federal, con cuya disposición pretendía el Constituyente que el número de ministros fuera determinado de modo limitado, pero razonable en cada Entidad Federativa, sin llegar al extremo de fijarlo en uno, ya que al decir "número máximo de ministros", se hacía referencia necesariamente a un número que esté en relación con otro y por lo mismo ese "máximo" no puede ser la unidad (DGCCJEH, 2006, p. 864).

Era esta una pequeña victoria legal, pero en la línea que venía luchando Guízar y Valencia, la de utilizar solamente las vías pacíficas y no dejar de agotar todos los procesos legales.

Un apoyo fundamental en la línea que perseguía el obispo fue el clero educado bajo su mandato. En efecto, ya desde I92I Guízar había colocado en un lugar principal de sus ocupaciones el seminario regional donde debían prepararse los aspirantes al sacerdocio. Muchas veces había tenido que meter dinero de su peculio para ayudar a su sostenimiento. En 1930, en un informe a la Santa Sede daba cuenta del crecimiento exponencial que había tenido el seminario a partir de su llegada a la diócesis: "En I92I el Seminario estaba aún a cargo de religiosos, quienes no llevaban matrícula. Probablemente serían en ese año Io alumnos. En los siguientes 9 años, a cargo el seminario del clero secular, se han matriculado 346 alumnos" (Guízar y Valencia, 1930, apéndice 8). De entre estos alumnos saldrían numerosos sacerdotes con la impronta del obispo Guízar y Valencia: trabajadores, abnegados, resilientes y orientados a la formación de un laicado participativo en el terreno de la política y exigente de sus derechos cívicos; combativo y, al 
mismo tiempo, alejado del recurso a las armas. No es de extrañar que, del clero de Chihuahua, bajo la égida de Antonio Guízar, resultaran obispos como Manuel Talamás y Comandari y Adalberto Almeida, y luchadores sociales laicos como Luis H. Álvarez.

\section{Conclusión}

La postura del arzobispo Guízar y Valencia, contraria a permitir la resistencia armada del laicado para conseguir diversas reivindicaciones de naturaleza religiosa, fue una convicción arraigada sobre todo en dos premisas: una de carácter filosófico teológico y, otra, de carácter político y práctico.

La primera era la certeza absoluta de que en México no estaban dadas las condiciones que señalaban algunos teólogos para resistir por medio de las armas a un gobierno opresor, sino sobre todo de que ese tipo de levantamientos únicamente originan males mayores de los que se pretenden evitar. Aceptó, por obediencia, la solución práctica que impusieron algunos de sus hermanos en el episcopado, esto es, la suspensión del culto; sin embargo, no dejó de combatir esta medida como un factor que apoyaba las tesis de los que consideraban que había llegado el momento de tomar las armas para obligar al gobierno a dar marcha atrás en sus disposiciones restrictivas. Estaba, por otro lado, convencido de que esa provisión del episcopado, estaba haciendo un gran mal a los fieles que, alejados de los auxilios espirituales ordinarios, se hallaban en riesgo de ir agostando su fe.

La convicción de carácter práctico tenía mucho que ver tanto con su experiencia reciente, como con su conocimiento de la historia de las

198 relaciones entre los diferentes gobiernos emanados del ámbito liberal. Para nadie era desconocido que, según el personaje que gobernaba, la situación de tolerancia u hostigamiento hacia la Iglesia podía variar enormemente. Por ello, ante un gobernante que apremiara el cumplimiento de las disposiciones constitucionales antirreligiosas, siempre vendría después otro que fuera más tolerante. Razón por la 
cual combatir al gobernante en turno por medio de las armas lo único que acarrearía sería una reacción de la misma índole y una cadena sin cuento de enfrentamientos armados entre los partidarios de la Iglesia y los seguidores del gobierno, de modo que, incluso si se llegara a remover al gobierno obteniendo así un régimen legal más propicio, se mantenía siempre abierta la puerta a un movimiento armado en sentido inverso que restaurase, incluso con mayores limitaciones, el régimen anterior. La solución, pues, no era otra, tanto para los laicos como para los eclesiásticos, que la de sobrellevar con paciencia las restricciones, fomentar la vida de oración y esperar la llegada de un gobernante con una visión más tolerante hacia la práctica religiosa, como lo había tenido en la persona del gobernador Ignacio C. Enríquez algunos años antes en Chihuahua. ${ }^{\mathrm{I}}$ No era, por tanto, un acomodarse a las cosas, ni por falta de fortaleza, ni por un perfil desdibujado y falto de convicciones; al contrario, era mantener sus convicciones firmes en contra del uso injustificado de la opción armada. Convicción que supo transmitir primeramente a su clero y, después, a los fieles laicos de su diócesis y que abonó para que, con algunas excepciones como el gobierno de Quevedo, durante el largo pontificado de Guízar y Valencia, Chihuahua contara con "la existencia de un catolicismo moderno, organizado en asociaciones movilizadas para la lucha cívica, capaz de 'perforar' el Congreso y el gobierno local con diputados 'revolucionarios' pero católicos” (Meyer, 2004, p. 7).

\section{Referencias}

AHAM. (1926). Carta de Antonio Guízar y Valencia, obispo de Chihuahua, a José Mora y del Río, arzobispo de México y Presidente del Comité Episcopal, Chihuahua, 8 de agosto de 1926 [Fondo episcopal: José Mora y del Río, caja I47, expediente 5].

AHAM. (1926). Carta de Pascual Díaz a Antonio Guízar y Valencia, Nueva York, 7 de agosto de 1928 [Fondo episcopal: Pascual Díaz, caja I4, expediente I6]. 
AHAM. (1927). Carta de Antonio Guízar y Valencia a Pascual Díaz, San Antonio, 25 de octubre de 1927 [Fondo episcopal: Pascual Díaz, caja 47, expediente 28 ].

AHAM. [Archivo Histórico de la Arquidiócesis de México]. (1925). Correspondencia entre Mons. Luis María Martínez y Adalberto Abascal [Fondo episcopal: Luis María Martínez, caja 33, expediente Io].

Alcalá, A. (20II). Gestación y realización de "los arreglos" (marzo a junio de 1929). En Libro anual de la Sociedad Mexicana de Historia Eclesiástica 20Io. La Iglesia en la Revolución Mexicana (pp. 215-27I). México: Minos IIIer. Milenio.

Belgodere, F., y Havers, G. (I993). Obispos mexicanos del siglo XX. Guadalajara: Libros católicos.

DGCCJEH. [Dirección General de Casas de la Cultura Jurídica y Estudios Históricos]. (2006). La Suprema Corte de Justicia y la Cuestión Religiosa 19I7-I94O. México: Suprema Corte de Justicia de la Nación.

El Universal. (1929, I5 de marzo). México.

González, J. (2009). La guerra de los cristeros y su licitud moral. México: Porrúa.

González, J. (2015), Desconcierto y desilusión de los católicos a causa de los arreglos. En J. Soberanes y O. Cruz (coords.), Los arreglos del presidente Portes Gil con la jerarquía católica y el fin de la guerra cristera. Aspectos jurídicos e históricos (pp. I33-I63). México: UNAM.

González, J. (2016). La paz que no fue. Boletín eclesiástico, (I0), 6I8-624. 
González, J. (20I7a). El registro de ministros de culto en México: de la limitación del número a la intromisión en la vida interna de las iglesias. Inclusiones, (4), 97-II2.

González, J. (20I7b). La guerra de los cristeros hitos y mitos. México: Panorama.

Guízar y Valencia, A. (1930, 3 de julio). Respuestas del obispo de Chihuahua al cuestionario enviado por la Sagrada Congregación de Seminarios en 1930. Recuperado de: http://www.clerus.org/clerus/dati/2006o6/IO-I3/Soto2.html

INEGI. [Instituto Nacional de Estudios de Estadística, Geografía e Informática]. (1996). Estados Unidos Mexicanos. Cien años de censos de población. Aguascalientes, México: INEGI.

INEHRM. [Instituto Nacional de Estudios Históricos de las Revoluciones en México]. (20I4). Diccionario de Generales de la Revolución (vol. 2). México: INEHRM / SEP / SDN.

L'Osservatore Romano. (I929, I5 de marzo). Roma.

La Prensa. [La Prensa. Único diario español e hispano americano en Nueva York]. (I929, I4 de mayo).

Marín, N. (1928). La verdad sobre Méjico. Antecedentes históricos, origen, desarrollo y vicisitudes de la persecución religiosa en Méjico. Barcelona: Tipografía Católica Casals.

Meyer, J. (I973). La Cristiada I. La guerra de los cristeros. México: Siglo XXI.

Meyer, J. (2004). Pro Domo mea: "La Cristiada" a distancia (Documentos de trabajo, número 29). México: CIDE. 
Meyer, J. (2013). De una revolución a la otra. México: El Colegio de México.

Navarrete, F. (1957). De Cabarrús a Carranza. La legislación anticatólica en México. México: Jus.

O’Dogherty, L. (200I). De urnas y sotanas. El Partido Católico Nacional en Jalisco. México: CONACULTA / UNAM.

Ortiz, J. de J. (I90I, I de noviembre). Carta Pastoral dirigida desde su antigua sede a sus nuevos diocesanos. Chihuahua: Boletín Eclesiástico de Guadalajara.

Pío XI. (I926, 2 de febrero). Litterae apostolicae. Recuperado de: http://w2.vatican.va/content/pius-

xi/la/apost_letters/documents/hf_p-xi_apl_19260202_paternasane-sollicitudo.html

Savarino, F. (20I7). El conflicto religioso en Chihuahua. Ciudad Juárez, México: El Colegio de Chihuahua / Universidad Autónoma de Ciudad Juárez.

Solis, Y. (2008). Asociación espiritual o masonería católica: la U. Istor (33), I2I-I37.

Valvo, P. (2016). Pio XI e la Cristiada. Fede, guerra e diplomazia in Messico (I926-I929). Brescia: Morcelliana.

\section{Notas}

${ }^{\mathrm{I}}$ En Guanajuato la población había disminuido 220,000 habitantes y en Morelos el 40\% (INEGI, I996).

${ }^{2}$ Por aquella época, Cotija tenía un poco menos de 6,00o habitantes. Sin embargo, antes de ser arrasada por el guerrillero José Inés Chávez García -en marzo de I9I8- era

Debates por la Historia -Artículos 
una de las poblaciones michoacanas con mayor prosperidad económica y cultural: contaba con dos bancos, una cigarrera, varias fábricas de chocolate, la producción del afamado queso Cotija... Desde el punto de vista cultural, gozaba de orquesta, biblioteca, una extensión del seminario de Zamora y los poetas Jesús González Valencia y José Rubén Romero comenzaban a destacar.

${ }^{3}$ A partir de 196I tuvo como auxiliar al obispo Luis Mena Arroyo, quien fue nombrado su coadjutor en I964; sin embargo, no lo sucedió en el cargo.

${ }^{4}$ La Liga Nacional Defensora de la Libertad Religiosa fue una organización cívica surgida con la idea de aglutinar a los católicos para defender los derechos que algunas leyes comenzaban a negarles. La idea de formar una asociación de ese tipo venía desde una década atrás; sin embargo, fue el intento de crear una iglesia cismática que reemplazara la Iglesia católica auspiciado por la CROM lo que llevó a los católicos a rápidamente organizarse en forma defensiva a principios de 1925.

${ }^{5}$ La encíclica Rerum novarum, del papa León XIII, data apenas del año I89I. En México tuvo una rápida difusión y dio lugar a lo que se conoce con el nombre de "catolicismo social".

${ }^{6}$ Entre el pontificado de José de Jesús Ortiz y el de Antonio Guízar y Valencia, gobernó la diócesis durante I8 años Nicolás Pérez Gavilán, quien continuó la obra iniciada por Ortiz, consiguió que se abrieran algunas escuelas católicas en el estado y que la labor pastoral de la diócesis se viera auxiliada por diferentes congregaciones religiosas.

${ }^{7}$ La tentación de mezclar la religión con la política y, quizá más aún, de servirse de la religión para la política, no era extraña en las asociaciones cívicas que se alzaban en una supuesta defensa de los derechos de la Iglesia, de ahí que el papa Pío XI, en carta del 2 de febrero de 1926, pidió expresamente a los obispos que la Acción Católica, los prelados y el clero, como tales, se abstuvieran de participar en política. Esto para no dar pretextos a los adversarios (Pío XI, 1926). Nuevamente en diciembre de 1927, cuando ya en diversas regiones del país se había desencadenado el conflicto armado, la Santa Sede recordó a la jerarquía mexicana, a través del nuncio Fumasoni Biondi: "Deben los obispos no sólo abstenerse de apoyar la acción armada, sino también permanecer fuera y por encima de todo partido político, aunque sea bueno y honesto" (Meyer, I973, p. I8).

${ }^{8}$ Valvo (2016) rescata un documento que permite ver cómo, por esas fechas, el arzobispo de México ponía "todas sus esperanzas en una próxima revolución que nos libere del actual gobierno" (pp. II6-II7).

${ }^{9}$ La solicitud fue desechada por I7I votos contra I (Marín, I928).

${ }^{\text {Io }}$ La Liga Nacional Defensora de la Libertad Religiosa fue una organización cívica compuesta por laicos católicos, entre ellos, algunos de los que habían formado parte del extinto Partido Católico Nacional. Se fundó en 1925 con el fin de salvaguardar las libertades fundamentales. Bajo el supuesto de que estaban defendiendo la Iglesia, se 
ostentaron como autoridad competente para coordinar las protestas de los católicos, incluida la resistencia armada.

${ }^{\text {II }}$ Para profundizar en el tema de la Guerra Cristera se puede revisar a Meyer (I973 y 2004), Valvo (20I6) y, lo que podría significarse como una historia mínima del conflicto, González (20I7b).

${ }^{12}$ Lo mismo hicieron los obispos de Querétaro, Francisco Banegas, y de Papantla, Nicolás Corona.

${ }^{\text {I3 }}$ Ignacio C. Enríquez gobernó Chihuahua en dos periodos; durante el segundo, de I9I8 a I924, coincidió con el obispo Guízar, con quien hubo gran entendimiento de cara a evitar confrontaciones y solucionar diferendos.

Este artículo se publica bajo una licencia de Creative Commons Reconocimiento-NoComercial 4.0
Internacional, y puede ser usados gratuitamente para fines no comerciales, dando los créditos a los
autores y a la revista.

